\title{
Academic Perceptions of Immigrant and Minority Postsecondary Students
}

\author{
Bette DeBellefeuille and Philip C. Abrami*
}

\begin{abstract}
This investigation compared postsecondary students whose mother tongue was English and who were natives of Canada $(N=117)$ with minority students $(N=91)$ in terms of: a) the perceived importance of a university education and the perceived likelihood of academic success; $b$ ) the estimated likelihood of success at both competitive and noncompetitive tasks; c) the causal attributions for task outcomes and affective reactions to those outcomes and d) one projective and four objective fear of success (FOS) measures. English Canadian students and minority students held equivalent views on the importance of a university education and a successful career. FOS scores did not differ between the groups regardless of the measure used, either for males or females. Although there were few differences between the groups in their reaction to competitive, achievement-oriented tasks, there were more differences between the groups in their reactions to noncompetitive tasks. Here, minority students expressed some negative affective reactions. The minority students believed that external factors, particularly luck, had a greater influence on task outcome than did English Canadians.
\end{abstract}

\section{RÉSUMÉ}

L'enquête avait pour but de faire ressortir les différences entre des étudiants nés au Canada et dont la langue maternelle est l'anglais $(N=117)$ et des étudiants provenant de groupes minoritaires $(N=91)$, sous le rapport de a) l'importance qu'ils attachent à une formation universitaire et au degré de succès qu'ils estiment

*Department of Education, Concordia University

This work was partially sponsored by a grant to the second author from Formation de chercheurs et action concertée, Ministère de l'Education, Gouvernement du Québec.

An earlier version of this paper was presented at the annual meeting of the International Congress of Psychology, Acapulco, Mexico, September, 1984.

Requests for reprints should be addressed to Philip C. Abrami, Education Department, Concordia University, 1455 de Maisonneuve Blvd. W., Montreal, Canada H3G 1M8.

The authors are indebted to the late Esther Massa who so diligently typed the handwritten responses to the projective FOS story leads.

The coders were Regina Ullrich, Miranda D'Amico, Mitchell Hoffman, and the first author. The average correlation between the coders' scoring and the scores for practice sets E-H provided by Horner and Fleming (1977) was 0.75. 
obtenir; b) la probabilité de réussite dans des tâches avec l'élément de concours et des tâches sans l'élément de concours; c) les causes attribuées aux résultats des tâches accomplies et les réactions affectives à la suite des résultats; $d$ ) une mesure projective et quatre mesures objectives de la crainte de succès (CDS). Les étudiants canadiens de langue anglaise et les étudiants minoritaires ont manifesté des vues plus ou moins semblables sur l' importance d' une formation universitaire et d'une carrière professionelle réussie. Les points pour le CDS n'indiquent aucune différence chez les deux groupes, indépendamment de la mesure utilisée ou du sexe de l'étudiant. La réaction des deux groupes aux tâches exigeant pour les accomplir plus d' effort de concurrence varie très peu; par contre, dans le cas de tâches où la concurrence ne joue aucun rôle, on observe plus de différences entre les deux groupes. Dans ce dernier cas, on remarque chez les étudiants minoritaires des réactions affectives de caractère négatif. Les étudiants minoritaires, plus que les canadiens de langue anglaise, estiment que d'autres facteurs (surtout la chance) ont une plus grande influence sur le résultat des tâches.

The academic performance of postsecondary students depends on a variety of factors other than student ability, including individual difference variables such as demographic (e.g., gender, SES) and personological (e.g., achievement motivation) factors. Among the more difficult tasks facing an instructor is how to facilitate the performance of students who differ on a host of characteristics. While of longstanding interest, knowledge of the factors that affect student learning has become increasingly important as the nature of the postsecondary school population becomes increasingly diverse.

Explanations for differences in achievement motivation have been found in the study of causal attributions. According to attribution theory (Weiner, 1980) a student's beliefs about the cause of past performance affect that student expectations about future success, emotional reactions to that performance, and future ontask behaviour.

Students typically attribute course performance to factors such as effort, ability, luck, and task difficulty. Causal attributions relate to academic behaviour in the following manner: if a student believes that his success on an exam was due to his hard work the chances of that student exerting similar or increased effort for future tasks are greater than if he believes that he succeeded because of luck. This study explores the academic beliefs of minority and anglophone students, which might influence their academic achievement.

From the cross-cultural research on student academic attributions one may learn about the generalizability of the attribution model, for example, whether a universal tendency exists to attribute success internally. One may also learn more about the antecedent conditions which cause individuals or groups to form different beliefs. To what extent is culture one of these conditions?

The research on cultural differences in attributions grew out of a 1973 study by Weiner and Peter that explored developmental and racial differences in achieve- 
ment judgments for black and white children living in the United States. With increasing age, effort expenditure grew in importance as a causal attribution and became the most influential factor among white 10-12 year olds. However, for teenagers there was an increasing diminution in the importance of effort expended for evaluative judgments. For teenagers, achievement products (success or failure) counted more than the individual effort exercised to achieve those products. Weiner and Peter (1973) speculated that this "regressive" tendency among older subjects was a function of the reward contingencies in the environment. They found the same regression effect among black and white students but it occurred at an older age for black students, which would mean that black and white children in the same class would have different attributional beliefs.

Salili, Maehr, and Gillmore (1976) replicated Weiner and Peter's 1973 study in Tehran, Iran, a culture radically different from North America, and found that effort was always the most influential variable in causal beliefs. The importance of effort in achievement judgments increased with age even among teenage subjects. In Iran it was more important to appear to be trying hard than it was to succeed. Salili et al. (1976) attributed differences between the studies to differences in culture-based learning experiences.

Most studies of cross-cultural differences in causal attributions have compared samples from different countries (Chandler, Shama, Wolf, \& Planchard, 1981; Harnisch \& Ryan, 1983; Rogers, 1980). Although this research has found cultural differences in attributions, they have been small and are overshadowed by the similarities between ethnic groups. Other studies focused on differences within countries between minority and majority students' causal beliefs (Massey \& Darnbusch, 1976; Fry \& Ghosh, 1980; Raviv, Bar-Tal, Raviv, \& Bar-Tal, 1980; Willig, Harnisch, Hill, \& Maehr, 1983).

Research with minority students has not always shown consistent differences between blacks and whites (Willig et al., 1983). Nicholls (1978) discovered group differences between minority Polynesian and majority white children in New Zealand which were highly age-related. Ethnic differences which were apparent in the beliefs of seven year olds did not exist in thirteen year olds.

In their 1980 study, Fry and Ghosh suggested that either the different cultural upbringing of the Canadian Caucasian and the Asian Indian subjects or the self-perception of the Asian Indians as having "minority group status" could explain the different causal beliefs of the two groups. The Canadian Caucasian subjects claimed internal causes for success and external ones for failure, while the Asian Indians' attributions were the opposite. According to Fry and Ghosh, the minority status effect challenges the competence and self-worth of immigrant and minority members who feel outcast from the dominant culture. This leads to these debilitating beliefs.

Maehr and Nicholls (1980) argue that situational determinants, especially when considered cross-culturally, and diverse conceptions and modes of achievement in different cultures produce culture-specific orientations toward achievement. Success and failure are viewed differently in different cultures, when there is 
cultural variation in the personal qualities that are desirable. These differences will give rise to differences in the perceived causes of success and failure.

Unfortunately most of the cross-cultural attribution research has been done with students in elementary and secondary school. Do the causal beliefs of minorities become closer to those of the mainstream as they grow older or do people maintain different academic beliefs into adulthood? This is a practical question that has implications for the instruction of college students. Murray and Mednick (1975) found that black college students were usually more likely to attribute achievement outcomes to luck than other attributional factors compared to white college students, while Munro's (1979) study of Zambian African, Zimbabwe-Rhodesian African, and Zimbabwe-Rhodesian European college and university students' beliefs showed few cultural differences.

Cross-cultural research has many methodological problems. How can one be certain that the subjects responses are not a reaction to the experimenter, the dependent measures, or the experimental setting (Triandis, 1972)? With the use of college students as subjects an attributional researcher can be more certain that subjects will have had experience with the type of tasks and situations employed in data collection.

The data on cultural differences in student academic beliefs does not reveal consistent differences between immigrants or minorities and natives. Unfortunately, differences (e.g., educational level, sex, age, race, SES, hypothetical vs. actual outcomes, self vs. other perspective, etc.) between studies do not allow a ready comparison of studies nor clear integration of the literature. Consequently, it is not clear the degree to which cultural variation produces differences in the perceived causes of success and failure. The studies which report cultural differences may be confounded by other individual and contextual effects. Further research is needed to determine the relationship between cultural learning experiences and academic beliefs.

The influence of culture may be greater as an indirect process; for example, as immigrant and minority students attempt to acculturize themselves to the dominant culture. That is, differences in cultural learning may allow minority status effects to operate and affect students' academic beliefs. Furthermore, research on culture and academic attributions has not explored cultural differences in students' affective reactions to academic outcomes. Understanding the emotional responses of students may help explain differences between groups in orientations to learning and academic behavior.

According to Horner's FOS hypothesis (1972), individuals high in FOS, especially women, tend to avoid achievement situations where they anticipate negative outcomes following success, including ridicule, loss of femininity, etc. Consequently, high FOS individuals may have different career and family aspirations and different reasons for their aspirations compared to low FOS individuals. According to the FOS hypothesis, high FOS individuals should prefer noncompetitive tasks to competitive ones. While the initial concern of this project was to explore sex differences in achievement motivation and validate various fear 
of success (FOS; Horner, 1972) measures, we became concerned that the diverse cultural and linguistic background of participants might mediate the relationships we explored. Would, for example, FOS be greater among immigrant females because of differences in their socialization patterns? Are there cultural effects on achievement attributions which are further enhanced in immigrant students?

The causal beliefs of immigrant and minority postsecondary students might be different than English Canadian students due to their different cultural and linguistic backgrounds. Furthermore, differences may exist due to the social, academic and other difficulties faced by minority students (Loo \& Rolison, 1986). For example, minority students might make greater external and unstable attributions because they perceive that events are not under their control, or are due to bad luck, or are due to the bias and prejudice of others, etc.

The present investigation compares postsecondary students whose mother tongue is English and who are natives of Canada with other students in terms of: a) the perceived importance of a university education; b) the estimated likelihood of success at both competitive and noncompetitive tasks; c) the causal attributions for task outcomes and affective reactions to those outcomes and d) one projective and four objective FOS measures.

\section{METHOD}

\section{Subjects}

The participants were 208 university and junior college students enrolled in 20 classes taught at anglophone institutions in the Montreal area during the 1982-1983 academic year. Students listed their first language and the country in which they were raised. Student responses to these two questions were used to assign students to two groups: a) English Canadian $(\mathrm{N}=117$ ) and b) True Minority $(\mathrm{N}=91)$. which included Italians, Greeks, Spaniards, Lebanese, Iranians, Chinese, Indian, etc. The True Minority subjects were those whose mother tongue was other than English or French or who were raised in a country other than Canada, the United States, England or France. ${ }^{1}$

\section{Instruments}

Each participant completed a questionnaire divided into three parts. Part I was a projective FOS measure (revised by Horner, \& Fleming, 1977). It consisted of four ambiguous story leads, one per page, arranged in random order for each student. The story leads were:

Jim is sitting in a chair with a smile on his face.

Linda is looking out at the sunset.

Jane is going back to the office at the end of the day.

John is looking into his microscope.

Students wrote a short story from each of these leads. 
Part II consisted of a series of multiple choice questions designed to assess student demographic characteristics, family and career aspirations, causal attributions for competitive and noncompetitive achievement-oriented tasks, and affective reactions to competitive and noncompetitive tasks (See Tables $3 \& 4$ ). Subjects were asked questions about their age, gender, academic major, and grade average and about their family and career aspirations and the factors which affected these aspirations (See Tables $1 \& 2$ ). On a seven point scale with 1 labelled "NEVER" and 7 labelled "ALWAYS", subjects responded to such questions as "Rate the extent to which you have had each of the following feelings as a reaction to competitive, achievement-oriented tasks: stress, frustration, anxiety, ... etc." Students ranked the degree of their negative feelings because high FOS subjects can become negatively aroused, especially in competitive situations.

In Part III, students completed one of four objective FOS measures, which were randomly distributed to subjects. The Good and Good (1973) scale contains 29 true-false items. The Pappo (1972) scale contains 83 true-false items. The Cohen (1974) scale contains 64 true-false items. The Zuckerman and Allison (1976) scale contains 27 items rated on a seven-point continuum from strongly agree to strongly disagree.

\section{Procedure}

Students completed the questionnaires during regular class periods and were given approximately 45 minutes to do so. Research assistants monitored the classes, answered questions and provided an oral debriefing for interested students at the conclusion of each class period.

Students were cautioned not to exceed more than half of the class period to complete Part I, the projective FOS measure. The four objective FOS measures employed in Part III were randomly attached to the questionnaires and distributed equally in each class.

\section{RESULTS}

The major findings of the study are the lack of differences between minority and majority subjects on the projective and four objective FOS measures. More specifically, no significant effects $(p>.05)$ between English Canadian students and minority students on any of the FOS measures were found. Since it was hypothesized that sex differences in FOS might be greatest for minority students, the interaction effect of gender and minority status on FOS was explored. Here too, no significant differences ( $p>.05$ ) were found.

For the remaining analyses, the questionnaire items were treated in groups and multivariate analyses were computed (followed by univariate ones) to increase statistical power and control error rate. For these analyses group identity (English Canadian, True Minority) was used as the single independent variable. In addition, a series of two-way analyses was computed, alternately using age, 
Table 1

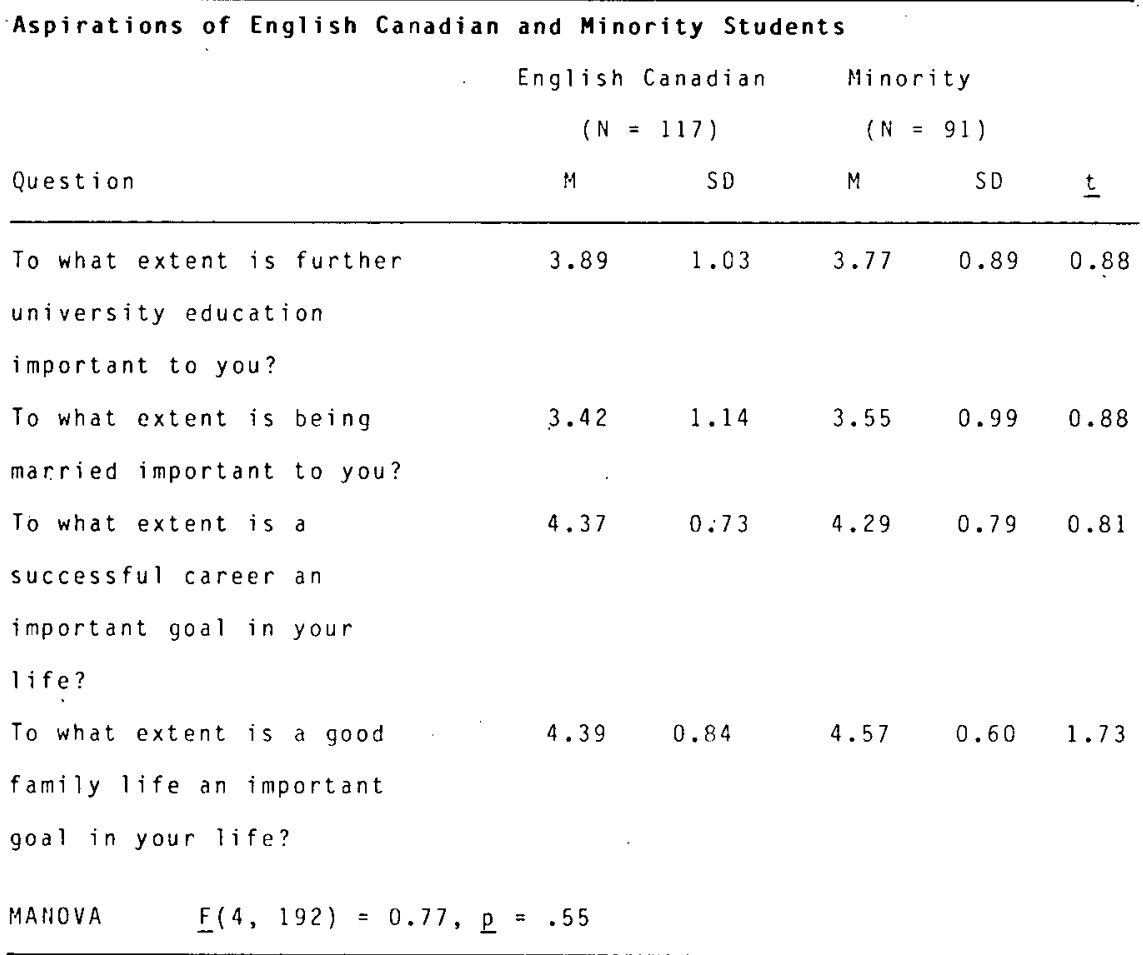

gender, academic major, and grade average as independent variables, in addition to group identity. Few significant interactions with group identity were found and there was no discernible pattern to them. Consequently, these results are not described in detail.

As described in Table 1, there were no general or specific differences in the aspirations of English Canadian and minority college students. Interestingly, both placed slightly greater importance on career and family goals than educational ones.

While native and immigrant students may aspire to similar goals, the reasons behind their aspirations may differ. To explore this possibility students were asked to rate the factors which most influenced their aspirations. Overall, there were no differences between the groups as suggested by the nonsignificant multivariate $F \mathrm{~s}$ reported in Table 2. However, minority students described peer pressure as having a greater impact on both career and family aspirations than native students.

English Canadian students reported similar success rates at competitive tasks compared to minority students. Interestingly, the average self-report success rates for both groups exceeded the scale midpoint (See Table 3). 
Table 2

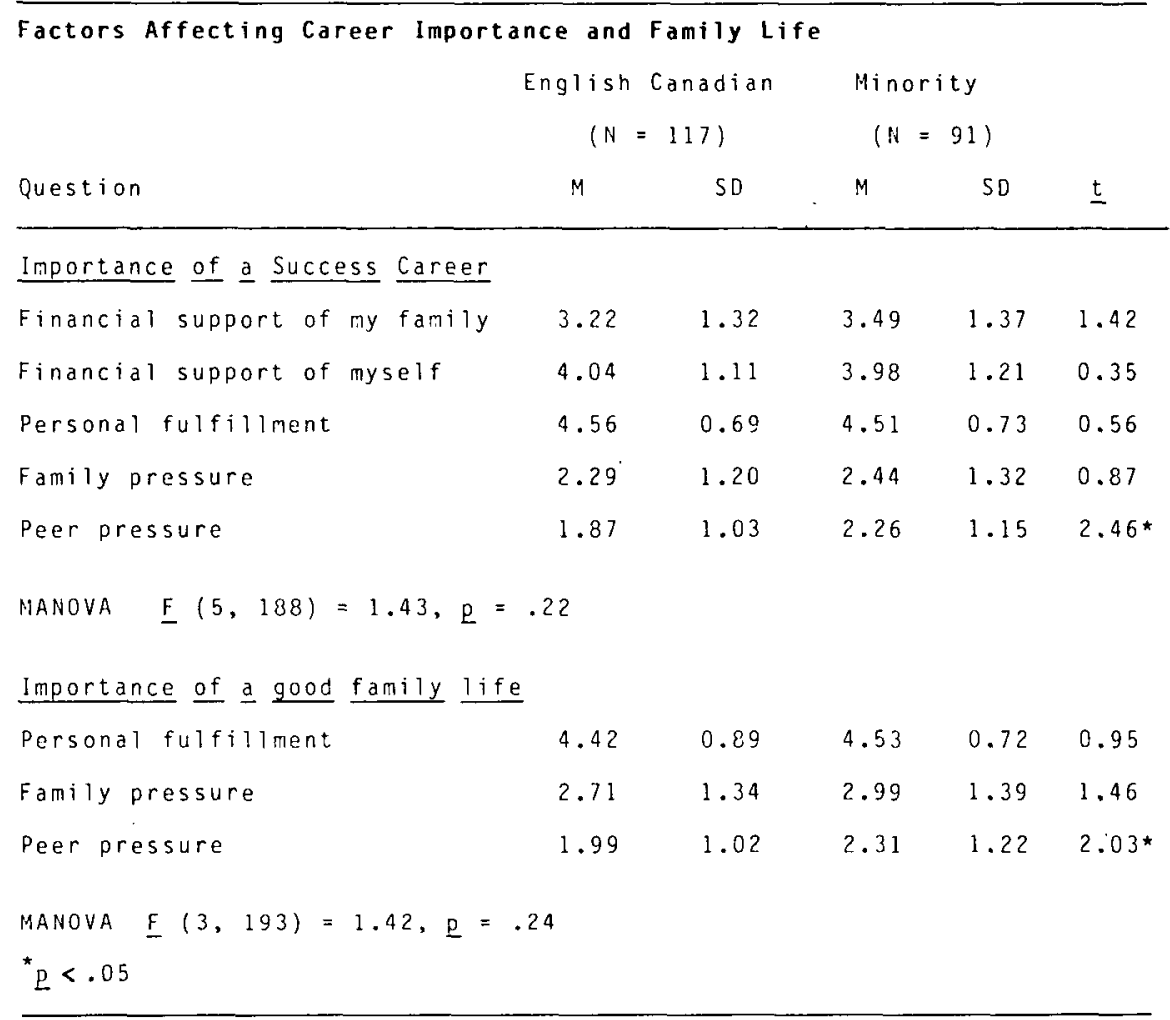

As Table 3 shows, the groups generally differed in their affective reactions to competitive situations. The minority students generally reported higher levels of negative affect, especially anxiety and (interestingly) boredom. Note, however, that the largest differences were rather small - less then one-half scale point on a seven-point scale.

The groups did not differ in attributing the causes for their usual performance at competitive tasks. Personal effort and ability, both internal factors, were seen as the most influential causes. The effort and ability of others and task difficulty, all external factors, were less important. Luck was the least influential cause.

Turning to noncompetitive tasks (see Table 4), again no differences were found between the two groups in perceived rate of success. Both groups described themselves as reasonably successful when the task is a noncompetitive one. But there were general differences between the groups, albeit small, in both depression and luck as evidenced by the significant multivariate effects reported in Table 4.

Generally, the groups differed in causal beliefs concerning noncompetitive tasks. Specifically, the minority students attributed significantly more responsibility to luck than the English Canadian students. There was also more negative 
Table 3

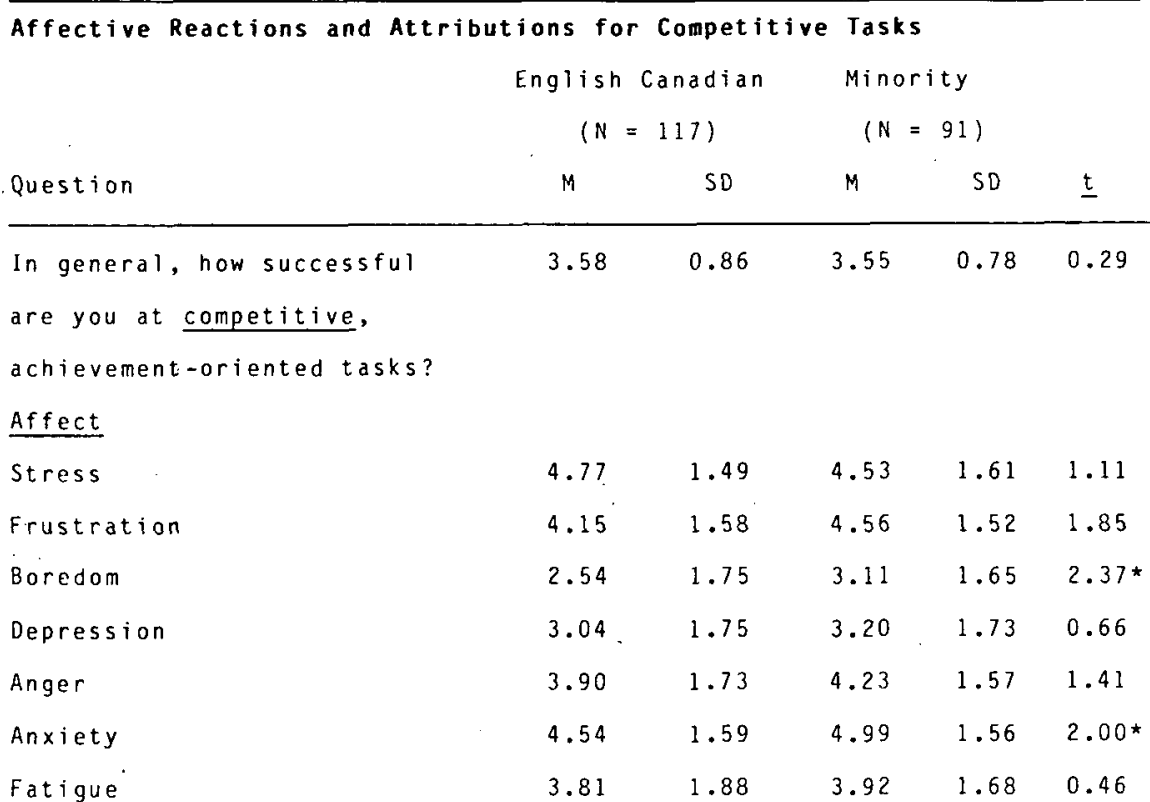

MANOVA $\underline{F}(7,190)=2.57, \underline{p}=.02$

Attributions

$\begin{array}{llllll}\text { Luck } & 2.85 & 1.54 & 3.02 & 1.51 & 0.80 \\ \text { Task difficulty } & 4.80 & 1.47 & 4.61 & 1.49 & 0.92 \\ \text { My personal effort } & 6.27 & 0.95 & 6.25 & 0.97 & 0.18 \\ \text { My personal ability } & 5.90 & 1.10 & 6.12 & 1.08 & 1.43 \\ \text { The effort of others } & 4.00 & 1.74 & 3.78 & 1.78 & 0.90 \\ \text { The ability of others } & 4.00 & 1.91 & 3.79 & 1.85 & 0.80\end{array}$

MANOVA $\underline{F}(6,193)=1.38, \underline{p}=.23$

$\star \mathrm{p}<.05$

affect among minority students than English Canadian students, especially depression. It is worth noting that for both student groups the absolute levels of negative affect were low: the highest affective mean rating was 3.62 even though the low anchor of the scale (1.00) was labelled "never".

The final analyses compared within group student reactions on competitive tasks to reactions on noncompetitive tasks. While English Canadians perceived greater success at noncompetitive tasks compared to competitive ones, $t(110)=$ 
$2.85, p<.05$, minority students perceived no difference, $t(88)=1.20, p>.05$. Both groups perceived significantly more negative affect with competitive tasks. The exception was boredom which received a significantly higher rating for noncompetitive tasks.

Attribution ratings did not vary dramatically for either group across task types. No differences were found between tasks for attributions to stable factors for either English Canadians (for task difficulty: $t(112)=0.94, p>.05$; for ability: $t(112)$ $=1.12, p>.05$ ) or minority students (for task difficulty: $t(87)=0.44, p>.05$; for ability: $t(87)=1.46, p>.05$ ). Both groups made greater attributions to unstable factors when the task was described as competitive, albeit in slightly different ways. English Canadians made greater attributions to luck, $t(111)=$ $2.75, p<.05$, but not effort, $t(112)=1.27, p>.05$, when the task was described as competitive. In contrast, minority students made greater attributions to effort, $t(87)=2.12, p<.05$, but not luck, $t(87)=0.34, p>.05$, when the task was described as competitive.

\section{DISCUSSION}

Surprisingly few differences were found between the academic beliefs of English Canadian and minority postsecondary students. First, FOS scores did not differ between the groups regardless of the measure used, either for males or females. A subject's minority status did not create greater FOS among minority female students compared to English Canadian females. Second, the two groups held similar views on the importance of a university education, the importance of a successful career, and with the exception of peer pressure, the factors that influence aspirations. Third, there were no differences between the groups in perceived success at either competitive or noncompetitive tasks. Fourth, causal beliefs of English Canadian and minority students were similar except for luck attributions in noncompetitive situations. Students believed that the internal factors of ability and effort determined task outcome more than the external factors of luck and task difficulty. Students also believed that unstable factors, either effort or luck, were more important in competitive situations than noncompetitive ones. However, there were small, general (i.e., multivariate) differences between the groups in affective reactions: the minority students usually experienced more negative reactions.

The greater negative affect among minority students, regardless of the type of task, suggests that while minority postsecondary students have similar aspirations to English Canadians, similar success expectations, and mostly similar beliefs about the causes of achievement outcomes, minority students have a slightly greater emotional concern with their educational performance. This somewhat greater aversive affect may represent what remains of cultural differences and/or the perception of minority group status. The minority student may view noncompetitive tasks with greater dislike and as less personally controllable because task rules are less well defined or because social interactions may occur which place the minority student at a disadvantage. 
Table 4

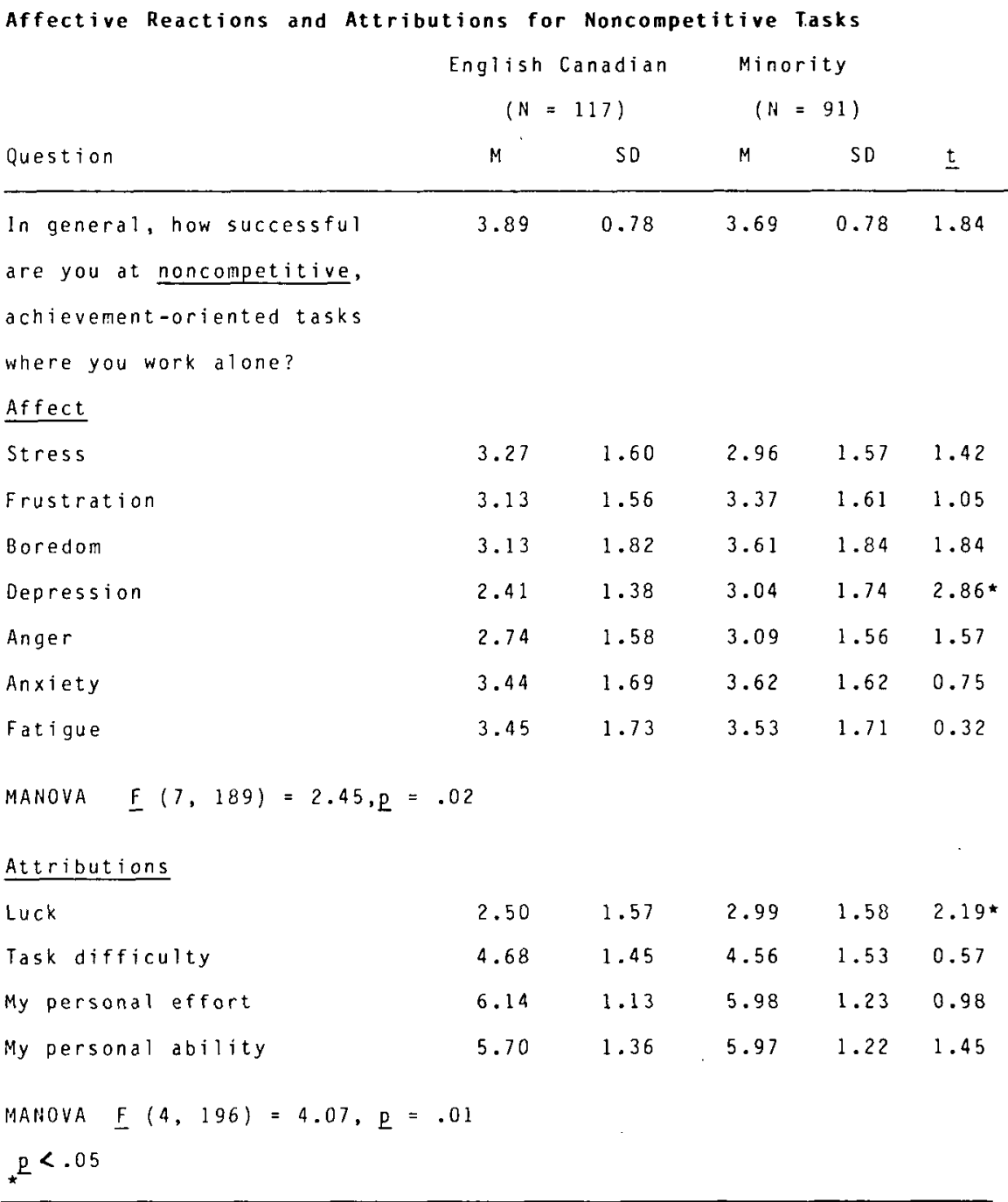

Nevertheless, the major finding in this study is the few differences which were uncovered in the motives, aspirations, beliefs, and feelings of native and minority postsecondary students. The absence of large differences between native and minority students in causal attributions is similar to the findings of Chandler et al. (1981) who investigated the academic beliefs of college students between countries and only found significant differences between cultures in luck attributions.

The research that has found larger cultural differences in attributions has been with younger subjects (Fry \& Ghosh, 1980). This may indicate that students 
initially have different academic beliefs but have adopted the beliefs of the majority by the time students are in college or university. Longitudinal studies of children's academic beliefs may uncover this tendency.

Perhaps so few differences were found because of limitations of the study. The questionnaire did not go into greater detail about such factors as the subjects' length of residence in Canada, their degree of facility with English, etc. which might mediate the effects of minority status. Also unexplored were the interactive effects of socioeconomic status which Raviv et al. (1980) believe is a more important factor than ethnicity. Furthermore, it may be that college and university admission requirements removed discrepant students from the sample. Finally the results may be a function of the improved education and socialization of minorities, especially in Canada where multiculturalism is encouraged.

This research has implications for future research on both the fear of success construct and the education of minority students. As we found no differences in the projective and objective FOS scores of male and female minority or majority students the concept of FOS needs to be examined further. Perhaps this trait may have existed in the 1960's when it was first identified by Horner (1968), but has diminished due to a decrease in sex-role stereotyping during the last two decades. There are problems associated with the reliability and predictive validity of the fear of success measures and further research is needed to determine whether this construct is still valid.

What are the implications of this research for the higher education of students in a multicultural society? We believe, but did not empirically validate, that some professors perceive differences in the way students of different ethnic backgrounds perceive their academic work. Is it that faculty expect minority students to have different academic beliefs or only notice the concerns of minority students because they stand out in class? This study suggests that for postsecondary students, such a belief by faculty is largely unfounded. Instructors should be aware of their biases and adjust their teaching accordingly.

\section{NOTE}

1. The data collected from anglophones from the U.S. or England or francophones from Canada or France $(\mathrm{N}=27)$ was coded as allied minority and was excluded from the analyses because these cultures do not differ significantly from that of English or French Canadians.

\section{REFERENCES}

Chandler, T. A., Shama, D. D., Wolf, F. M., \& Planchard, S. K. (1981). Multiattributional causality for social affiliation across five cross-national samples. Journal of Psychology, 107, 219-229.

Cohen, N. E. (1974). Explorations in the fear of success. Unpublished doctoral dissertation, Columbia University, New York. (University Micro-Films no. 75-78, 368).

Fry, P. S. \& Ghosh, R. (1980). Attributions of success and failure: Comparison of cultural differences between Asian and Caucasian children. Journal of Cross-Cultural Psychology, 11, 343-363. 
Good, L. R. \& Good, K. C. (1973). An objective measure of the motive to avoid success. Psychological Reports, 33, 1009-1010.

Harnisch, D. L. \& Ryan, K. E. (1983). An investigation of the relationship of achievement motivation with achievement in mathematics for students in the United States and Japan. Paper presented at the Annual Meeting of the Midwestern Educational Research Association. Kansas City, MO. September 29 to October 1.

Homer, M. S. (1968). Sex differences in achievement motivation and performance in competitive and noncompetitive situations. Dissertations Abstracts International, 30, 407 (University Micro-Films no. 69-R, 135.)

Homer, M. S. (1972). Toward an understanding of achievement-related conflicts in women. Journal of Social Issues, 28, 157-176.

Horner, M. S. \& Fleming, J. (1977). Revised scoring manual for an empirically derived scoring system for the motive to avoid success. Radcliff Data Resource and Research Center, 10 Garden Street, Cambridge, MA. 02138.

Loo, C. M. \& Rolison, G. (1986). Alienation of ethnic minority students at a predominantly white university. Journal of Higher Education. 57. 58-77.

Maehr, M. L. \& Nicholls, J. G. (1980). Culture and achievement motivation: A second book. In N. Warren (Ed.). Studies in Cross-Cultural Psychology, Vol. 2. London: Academic Press, pp. 221-267.

Massey, G. \& Dambusch, S. (1976). Self-enhancement, self-consistency, and distinctiveness of feedback in a field study of academic self-concept. (Tech. Rep. No. 49). Stanford: University of California.

Munro, D. (1979). Locus of control attribution: Factors among blacks and whites in Africa. Journal of Cross-Cultural Psychology, 10, 157-172.

Murray, S. R. \& Mednick, M. T. S. (1975). Perceiving the causes of success and failure in achievement: Sex, race, and motivational comparisons. Journal of Consulting and Clinical Psychology, 43, 881-885.

Nicholls, J. G. (1978). Development of causal attributions and evaluative responses to future success and failure in Maori and Pakeha children. Developmental Psychology, 14, 687-688.

Pappo, M. (1972). Fear of Success: A theoretical analysis and the construction and validation of $a$ measuring instrument. Doctoral Dissertation, Columbia University, (University MicroFilms no. 282-161).

Raviv, A., Bar-Tal, D., Raviv, A., \& Bar-Tal, Y. (1980). Causal perceptions of success and failure by advantaged, integrated and disadvantaged pupils. British Journal of Educational Psychology, 50, 137-146.

Rogers, C. G. (1980). The development of sex differences in evaluations of others' successes and failures. British Journal of Educational Psychology, Vol. 50, pp. 243-252.

Salili, F., Maehr, M. L., \& Gillmore, G. (1976). Achievement and morality: A cross-cultural analysis of causal attribution and evaluation. Journal of Personality and Social Psychology, $33,327-337$.

Triandis, H. C. (1972). The Analysis of Subjective Culture, New York: John Wiley \& Sons.

Weiner, B. (1980). Human Motivation. New York: Holt, Rinehart and Winston.

Weiner, B. \& Peter, N. (1973). A cognitive - developmental analysis of achievement and moral judgments. Developmental Psychology, 9, 290-309.

Willig, A. C., Harnisch, D. L., Hill, K. T., \& Maehr, M. L. (1983). Sociocultural and educational correlates of success - failure attributions and evaluation anxiety in the school setting for black, Hispanic, and Anglo Children. American Educational Research Journal, 20, $385-410$.

Zuckerman, M. \& Allison, S. N. (1976). An objective measure of fear of success: Construction and validation. Journal of Personality Assessment, 40, 422-430. 
